\title{
Analysis and Response of Tax Risk Based on the Way of Personal Income Tax
}

\author{
Hongmin Zhao ${ }^{1,}$, , Xueye Zhang ${ }^{2}$ \\ ${ }^{1}$ School of Economics, Shanghai University, Shanghai, China \\ ${ }^{2}$ Shanghai Internal Revenue Service, Shanghai, China \\ Email address: \\ 18721592579@163.com (Hongmin Zhao), 1872159597@163.com (Xueye Zhang) \\ ${ }^{*}$ Corresponding author
}

\section{To cite this article:}

Hongmin Zhao, Xueye Zhang. Analysis and Response of Tax Risk Based on the Way of Personal Income Tax. Science Innovation. Vol. 5, No. 6, 2017, pp. 420-423. doi: 10.11648/j.si.20170506.26

Received: December 1, 2017; Accepted: December 21, 2017; Published: December 28, 2017

\begin{abstract}
China's current individual income tax has a wide range of taxes, and there are many different kinds of tax obligations. China is also a large population, and individual income tax is paid mainly through withholding. In a volatile market, the boundary between withholding and paying taxes is easily blurred, resulting in a series of tax risks. In this paper, the author analyzes the tax payment and withholding tax in the tax sense; and explaining the confusion caused by the withholding and tax payment, and then explores the countermeasures from the perspective of tax authorities and enterprises.
\end{abstract}

Keywords: Personal Income Tax, Tax Withholding Agent, Amount of Taxable Income, Tax Payers

\section{代付个人所得税方式下产生涉税风险的分析与应对}

赵红敏 ${ }^{*}$ ，章雪野 ${ }^{2}$

1经济学院, 上海大学, 上海市, 中国

2 上海市国税局, 上海市, 中国

邮箱

18721592579@163.com（赵红敏）, 18721592597@163.com（章雪野）

摘要: 中国现行个人所得税的税目繁多, 纳税义务发生的情形多种多样。而中国亦是人口大国, 个人所得税主要通过 代扣代缴方式完成缴纳。在纷繁多变的市场上，代扣代缴和代付税款的界限容易被模糊，由此产生一系列涉税风险。 本文主通过案例分析, 从税收意义上对代付税款与代扣代缴两种缴税方式进行辨析; 阐释因为代扣代缴和代付税款方 式混淆, 从而引发的涉税风险并分别从税务机关和企业两个视角出发探索了应对策略。

关键词: 个人所得税, 代扣代缴, 代付, 应纳税所得, 纳税义务人, 扣缴义务人

\section{1. 引言}

改革开放30多年来, 中国居民的收入水平大幅提高, 相应的中国个人所得税在税收体系中所占的比重也越来 越大。从中国全国来看, 有相当多的城市, 个人所得税已
成为仅次于营业税的第二大地方税种,成为地方财政的重 要支柱之一。[1]个人所得税是中国国家收入二次分配的重 要资金来源, 所以完善税收制度有利于限制逃税、增加个 
人所得税征收的公平性。从而让税收更好的调节收入的再 次分配。[2]在现有的中国税法中个人所得税可以通过纳税 人自我申报、代扣代缴和代付税款等方式, 其中代扣代缴 方式是主要缴纳方式。与此同时, 在日常税收实务中, 代 扣代缴和代付税款的界限逐渐被模糊, 由此产生一系列涉 税风险。准确鉴别代扣代缴和代付税款是税务工作者和财 务工作者的重要工作。本文通过两个典型案例, 从税收意 义上对代付税款与代扣代缴进行辨析, 进一步分析代付税 款引发的涉税风险并分别从税务机关和企业两个视角出 发探索了应对策略。

\section{2. 现行个人所得税法的相关规定}

个人所得税是以自然人取得的各类应税所得为征税 对象而征收的一种所得税, 其纳税义务人除了具有自然人 性质的企业（如个人独资企业、合伙企业）之外，均为个 人。而中国人口数目庞大, 结合非居民纳税人等影响因素, 可以推知个人所得税, 具有税源广、形式多样、征管不便 的特点。[3]

因为个人所得税税源广而且征管不便, 所以中国纳税 义务人主要通过代扣代缴的方式进行缴纳。代扣代缴是依 照税法规定负有代扣代缴义务的单位和个人，从纳税人持 有的收入中扣取应纳税款并向税务机关解缴的一种纳税 方式。[4]凡支付个人应纳税所得的企业、事业单位、机关、 社团组织、军队、驻华机构、个体户等单位或个人, 为个 人所得税的扣缴义务人。[5]

中国现行的个人所得税法规定的税目共计十一项: 工 资、薪金所得; 个体工商户的生产、经营所得; 对企事业 单位的承包经营、承租经营所得; 劳务报酬所得; 稿酬所 得; 特许权使用费所得; 利息、股息、红利所得; 财产租 赁所得; 财产转让所得; 偶然所得; 经国务院财政部门确 定征税的其他所得。而根据规定, 通过代扣代缴方式缴纳 税款的税目范围覆盖个人所得税法中除个体工商户的生 产、经营所得之外的所有税目。[6]

\section{3. 代付税款对代扣代缴的替代作用与节税效应}

\section{1. 替代作用的形成}

纳税义务人 (因为代扣代缴义务人一般是个人收入的 付款方，所以与之对应以下称纳税义务人为收款方）取得 的收入在扣除个人所得税款后方为其实际所得。现实生活 中, 为数不少的收款方或是为了维持自己的收入总额不变, 抑或是出于其他需要会与付款方协商由付款方按税后金额 向其付款, 而税款由付款方直接向税务机关缴纳。此时收 款方所收款项的数值已经确定, 不论是将收款方的收入视 为含税收入, 还是不含税收入均不影响收款方的既得利益, 也就不会受到来自收款方的牵制。[7]而税务机关作为与扣 缴义务人直接联系的税款征收方, 无法核实收款方所得收 入是税前收入还是税后收入, 很大程度上只能被动接受扣 缴义务人所缴纳的税款。所以付款方在向税务机关付款时 出于对自身利益的考虑或者因为其他需求, 就会逐渐模糊
代付税款和代扣代缴税款的界限, 进而以代扣代缴为名, 行代付税款之实, 不知不觉中收获一定的节税效应。

\section{2. 节税效应的产生}

节税效应主要产生于税基大小的差异。[8]相比于税 后收入, 税前收入包含所得税的税款值。而根据现行个 人所得税法规定, 我国的个人所得税主要采用比例税率, 包括固定比例税率 (如偶然所得、其他所得、稿酬所得、 特许权使用费所得等) 也包括比例税率随应纳税所得额 增加而增加的超额累进税率（如工资薪金所得）。而根 据规定, 应纳税所得额在收入的基础上计算而成, 与收 入呈现正相关关系。结合以上两方面因素考虑, 以税前 收入为基数计算的应纳税额势必将大于等于以税后收入 为基数计算的应纳税额。扣缴义务人将收款方收入视为 税前收入的作法也就由此取得了节税效应。而且可以推 知, 这个节税效应随着收入绝对值的增加也在一定程度 上会被放大。

\section{4. 代付税款产生的税收风险论述}

代扣代缴作为个人所得税的一种主要征收方式, 却暗 含着巨大的节税空间, 这是因为离不开代付税款的应用。 而广大企业如果计算失当或者认知不到位就会导致存在 少缴税款的风险。下面由一个案例来具体阐述代付税款与 代扣代缴纳税方式的区别与联系, 并论述代付税款下税收 风险的产生机理。[9]

\section{1. 案例}

$\mathrm{B}$ 企业因为业务宣传需要, 随机向本单位以外的个人 赠送礼品, 自然人A收到礼品, 对于自然人A的此项礼品 所得，应按照“其他所得”项目，全额适用 $20 \%$ 的税率缴纳 个人所得税。

此时不妨假设该礼品价值 1000 元并且不考虑增值税、 城市维护建设税及教育费附加。

在代付税款的计算路径下, B企业将 1000 元视为 $\mathrm{A}$ 的 税前收入, 为 $\mathrm{A}$ 计算并缴纳个人所得税:

$$
1000 * 20 \%=200 \text { 元 }
$$

按此路径计算, A共收入 1000 元, B共付出 1200 元, 税务机关收到税款 200 元。

在代扣代缴税款的计算路径下，B企业将1000元视为 $\mathrm{A}$ 的税后收入, 为 $\mathrm{A}$ 代扣代缴个人所得税:

$$
1000 /(1-20 \%) * 20 \%=250 \text { 元 }
$$

按此路径计算, A共收入 1000 元, B共付出 1250 元, 税务机关收到税款 250 元。

经过比较可以发现, 两种路径下, $\mathrm{A}$ 的利益不受影 响, B在代扣代缴路径下需要多支付 50 元税款, 税务机 关在代付税款路径下相对于代扣代缴会损失 50 元税款。 所以 $\mathrm{B}$ 企业和税务机关就构成了计算路径选择的利益双 方。 


\section{2. 案例分析}

\subsection{1. 代付税款的实质与影响}

随意用代付税款路径替代代扣代缴税款来获取节税 效应是不具有合理性的。根本原因在于企业对 $\mathrm{A}$ 的收入范 围存在误解。如果将 1000 元判定为税前收入, 却由付款方 代替收款方仍额外向税务机关支付税款，而没有从 1000 元中扣取税款, 则必将导致付款方缴纳的税款成为了收款 方收入的一部分。应当与原收入合并计算。从另一个角度 理解, 收款方在收款时未从所收款项中分离税款并缴纳, 却由付款方代替已方承担支付税款的义务, 实质上使得付 款方为收款方承担了部分债务, 所以此部分被承担的债务 应当计入付款方的收入征税。

\subsection{2. 代付税款的实操缺陷}

以上文 (1) 中的案例为例, 继续讨论。A收入 1000 元的礼品为例, $B$ 将其缴纳的 200 元税款计入 $A$ 的收入再次 计算税款为:

$$
(1000+200) * 20 \%=240 \text { 元， }
$$

应补缴税款 $240-200=40$ 元

同理, $\mathrm{B}$ 将其缴纳的 40 元税款计入 $\mathrm{A}$ 的收入再次计算 税款为:

$$
(1000+200+40) * 20 \%=248 \text { 元， }
$$

应补缴税款 $248-240=8$ 元

如上, B 将其缴纳的 8 元税款计入 $\mathrm{A}$ 的收入再次计算税 款为:

$$
(1000+200+40+8) * 20 \%=249.6 \text { 元， }
$$

应补缴税款 $248-240=1.6$ 元

根据归纳可以发现，B企业如严格执行税法规定将无 数次补缴税款, 且每次补缴的税款以 $20 \%$ 为公比构成等比 数列。无论是补缴次数的无穷性, 还是一定次数后应纳税 款小于最小人民币单位 0.01 元, 两个因素都会导致B企业 在代付税款路径无法完税。

通过数学中的级数理论。所研究问题, 即为通项为求 $200 * 20 \% \wedge \mathrm{q}$ 构成的无穷项等比数列的和的极限。对该等比 数列求和并取极限为:

$$
\begin{aligned}
& \lim _{n \rightarrow+\infty} \sum_{i=0}^{n} 200 * 20 \%^{\wedge} i \\
& =200 \lim _{n \rightarrow+\infty} \sum_{i=0}^{n} 20 \%^{\wedge} i \\
& =250
\end{aligned}
$$

\section{2. 3. 代付税款与代扣代缴的联系和代付税款的节税来 源}

将极限结果 (250) 和 (一) 中代扣代缴计算路径下 的过程与结果相比较, 可以发现在正确认知代付税款的前 提下, 计算出的税款事实上与在代扣代缴路径下, 计算出 的结果是相同的。而从B企业角度发现表面上的产生的 50 元的节税效应其实是来自于仅申报一次税款之后所缺失
的其他应申报的税款。节税额即所应缴纳的税款与第一次 缴纳的 200 元的差额:

$$
\lim _{n \rightarrow+\infty} \sum_{i=0}^{n} 200 * 20 \% \wedge i-200=50
$$

\subsection{4. 本案中代付税款的涉税风险分析}

根据4中的论述不难得出, 代付税款计算路径下缴纳的 税款相比较代扣代缴计算路径下缴纳的税款带来的节税效 应实质上是一种少缴税款的行为。而根据现行的《中华人 民共和国税收征收管理法》规定，扣缴义务人不按规定履 行代扣代缴义务的, 税务机关负责向纳税人追缴税款, 但 对扣缴义务人将依《征管法》的规定除以应扣未扣税款 $50 \%$ 以上 3 倍以下的罚款。本例中 $\mathrm{B}$ 企业作为代扣代缴义务人, 少缴税款 50 元，根据此项规定会面临 25 至 150 元的罚款。而 $\mathrm{A}$ 作为纳税义务人, 也会面临被追缴50元税款的局面。

\section{3. 代付税款可能导致的其他潜在涉税风险浅析}

\section{3. 1. 计算企业所得税时少计应纳税所得额的风险}

因为付款方代收款方支付的税款来自于付款方, 并非 从收款方的收入中扣缴, 所以税款与收入的自然分离导致 其个人所得税表征不明显, 从而部分企业易将此税款支出 与费用类支出相混淆。比如企业如果在发放工资薪金时代 员工支付税款，容易将此部分税款单独计入管理费用。而 根据有关规定，雇主为雇员负担的个人所得税款，应属于 个人工资薪金的一部分, 凡单独作为企业管理费用列支的, 在计算企业所得税时不得扣除。[10]根据上文的论述，企业 为员工负担的个人所得税从本质上来说是员工个人工资薪 金收入的一部分, 如果单独在管理费用中列支，而在计算 企业所得税时又没有注意到不可扣除的规定, 就会多计扣 除项目而少计应纳税所得额。

\subsection{2. 会计科目错误导致的应纳税所得额计算错误风险}

接上文，如果将此部分税款单独在管理费用中列支， 除了可能导致多扣除费用的风险, 还有可能导致所计会计 科目错误进而导致应纳税所得额计算错误。假设针对销售 部门的销售人员的工资薪金个人所得税部分由公司代付, 这部分税款本来应该计入销售人员的工资薪金收入之后 计入销售费用, 而由于财务人员的疏忽大意将这部分税款 单独计入管理费用。对于个人所得税款的处理不当导致了 销售费用的少计与管理费用的多计。而销售费用中的广告 宣传费用与管理费用中的业务招待费在计算企业所得税 的应纳税所得额时采取的是限额扣除。尤其是业务招待费 扣除限额之一就是由管理费用为基础计算而来的。综上所 述，管理费用的错误计算将会影响应纳税所得额的计算。

\section{5. 该涉税风险的应对}

\section{1. 税务机关视角下该涉税风险的应对}

付款方选择代收款方支付的方式缴纳税款，根据上文 分析, 极易造成少缴漏缴, 而税务机关面临的监管最大障 
碍在于信息的不对称性, 所以可以考虑从能触及到的证据 入手确认收款方的收入究竟是含税收收入还是税后收入。

\subsection{1. 收入特殊性的判断}

如三 (一) 所举案例, $\mathrm{A}$ 自然人从 $\mathrm{B}$ 公司随机发放礼 品的活动中得到的是价值 1000 元的礼品, 而非现金 1000 元。而根据常识可以得知, 礼品一定是被 $\mathrm{A}$ 完整地收下, 而不可能被分割之后缴纳税款。所以对应的价值 1000 元一 定就是 $\mathrm{A}$ 的税后收入。计算上也应按照 1000/ (1-20\%) $* 20 \%=250$ 得出应纳税额。

从收入为实物的角度考虑, 税务机关应当留意收入不 可分割的特殊性从而将该部分收入判断为税后收入。

\subsection{2. 收款方的特殊性考虑}

在企业所得税后续管理的日常工作中, 经常遇到企业 雇佣老年人从事简单的工作的情形。对此企业为了证明支 出发生的真实性, 避免调增应纳税所得额或者补缴企业所 得税, 又无法提供支付工资的银行付款凭证, 就往往会声 明给这些人发放了现金并提供员工领取现金的签字记录。 而员工声明领取到手的现金, 其性质就是税后收入。同样 应当先换算成税前收入, 再按照个人所得税的规定计算缴 纳个人所得税。

从收入对象的特殊性出发, 如果收入对象留下任何 声明自己领取现金数目的记录, 则应当推知此为其税后 收入。

\subsection{3. 交易特殊性的监督}

存在相当一部分交易属于资料相对齐全的交易。这部 分交易如果涉及代扣代缴个人所得税则可以根据相关资 料上的文字说明进行判断。比如在进行房产交易时, 若买 卖合同上约定了收款方收取对价的数目, 则应当将其判断 为收款方税后收入。从交易特殊性入手, 如果该交易留下 的资料较多，则这些资料也可以帮助税务机关甄别收入的 性质。

\section{2. 企业视角下该涉税风险的应对}

\subsection{1. 少缴税款风险}

在上述案例中, $\mathrm{B}$ 企业代 $\mathrm{A}$ 支付税款, 因为计算原理 不恰当导致少缴税款 50 元。现实中, 扣缴义务人应当仔细 甄别收款方取得收入的性质, 必要时在合同等文件上应予 以明确标注。避免错用政策和少缴税款。

\subsection{2. 成本费用超支风险}

在上述案例中, 假设 $\mathrm{B}$ 企业举行的礼品随机赠送活动 预算仅仅 1200 元, 却因为按照代扣代缴的计算方式缴纳税
款造成超支 50 元。以此为例, 若要应对成本费用的超支风 险, 企业可以考虑将预算总额作为收入方的税前收入。从 预算总额中计算扣除税款以后, 用剩余的预算额进行活动 安排, 从而降低超支的风险。

\section{6. 结论}

代付税款不属于个人所得税法规定的税款缴纳方式 的范围, 其与代扣代缴方式有形式上的相似度, 在日常 税收实务中容易混淆, 这就给税收征收和缴纳都提出了 挑战。从征税方角度, 税务机关应该明辨两者差别, 从 税款的数目出发, 鉴别企业对税法遵从度, 防止偷税、 漏税。从缴税方角度, 企业和其他相关个人应该努力学 习税法知识, 遵守税法, 主动鉴别代扣代缴和代付两种 方式的不同, 防止因疏忽而出现漏税的情况。只有税务 机关加强辨析, 而企业也避免投机, 双管齐下才能切实 维护好个人所得税征收管理的秩序。

\section{参考文献}

[1] 岳希明、徐静等, 2012: 《2011年个人所得税改革的收入 再分配效应》, 《经济研究》第9期。

[2] 岳希明、徐静, 2012: 《我国个人所得税的居民收入分配 效应》, 《经济学动态》第6期。

[3] 经济转型期个人所得税征管面临的主要问题研究[J].赖永 芹.现代物业(中旬刊).2015(01)。

[4] 我国个人所得税的制度缺陷及改革思路[J].利雅.吉林省经 济管理干部学院学报.2015(03)。

[5] 避税权的法律性质及规制[J].王超.河北理工大学学报(社会 科学版).2007(04)。

[6] 论纳税义务及其履行 [J]. 吴希平, 阎建, 肖冰, 陈光宇. 税务 研究.2000(07)。

[7] 基于纳税服务的企业税收风险防范[J].曹阳, 李清.税收经济 研究.2017(03)。

[8] 现代税收管理过程中如何开展税收风险管理 [J].韩冬梅.纳 税.2017(26)。

[9] 基于公平收入分配视角的个人所得税改革探讨 [J].刘桂香. 安徽理工大学学报(社会科学版).2017(04)。

[10] 论个人所得税现行征收方式的弊端以及改革措施[J].侯娅 丽, 任珊.会计师.2017(18)。 